extreme difficulty confronting the salary earner in Britain of accumulating any capital. Both entrenched privilege and economic egalitarianism are believed to be aspects of the British scene that emigrants dislike. The views of British physicians who had emigrated to North America were analysed recently by T. C. Gibson, ${ }^{4}$ and though expressed in somewhat different terms they have many points of resemblance with those recorded in last week's report. The three main factors influencing their decision to emigrate were dissatisfaction with opportunities for promotion, the lure of better economic conditions, and dissatisfaction with conditions of work in the United Kingdom. On a specific question whether the decision to emigrate was influenced by conditions in the National Health Service Gibson found that the replies were evenly divided between yes and no.

The report's approach to halting the brain drain is, through a number of recommendations both to the Government and to industry, to try to make prospects in Britain so attractive that young people will prefer to remain here than to seek their fortune overseas. This surely is the right way, for medicine as well as for the non-medical occupations now reported upon. As much the largest employer of doctors, the Government has a special responsibility to make conditions of employment attractive if the present damaging flow of talent abroad is to be reduced to healthier proportions. And senior members of the medical profession too, especially those in a position to mould the future course of medical practice, have a responsibility to see that their juniors have decent prospects and opportunities.

\section{Surgery in Pulmonary Tuberculosis}

There are two main reasons for the recent decline in the necessity for surgical treatment of pulmonary tuberculosis. Firstly, the development of effective antituberculous chemotherapy has undoubtedly played the major part, and, secondly, there has been a notable improvement in general living conditions. Nevertheless, there is still a small but definite place for surgery in the treatment of pulmonary tuberculosis, ${ }^{1}$ and this is likely to remain so as long as the disease is present.

The few patients who still require surgical treatment to complete their recovery fall roughly into six groups. The first of these are those patients with cavitated disease who after six months of adequate chemotherapy are still producing positive bacillary tests, particularly where the original organism showed an appreciable degree of resistance to the standard antituberculous drugs. After a period of unsuccessful treatment the risk of the development of resistance increases steadily, while the patient's acceptance of his treatment-as well as the doctor's enthusiasm-may be sorely tried. Resection while antituberculous drugs are still effectual should therefore be carried out in these cases after the chest physician and thoracic surgeon have discussed all the factors concerned. The drugs should be continued after operation for three months to one year according to the severity of the disease.

The second group comprises those patients who have an undiagnosed nodular lesion on the chest radiograph, particularly those over the age of 40 . Frequently it is possible to make a differential diagnosis only of tuberculosis, carcinoma, or a lesion such as hamartoma, and hence resection should be carried out. If the lesion is found to be tuberculous the patient's antituberculous chemotherapy should be continued, and he should be allowed to return to his normal activities fairly rapidly.

The third group contains those patients who are left with troublesome residual damage from earlier pneumothorax therapy, or from other forms of collapse therapy such as plombage. Here the problem is usually that of an empyema, and often even many years later tubercle bacilli can be recovered from the fluid. Hence these lesions should be removed, and total pleurectomy may well be needed. The fourth group of patients who may need operation are those who suffer from repeated or severe haemoptysis. This usually originates from bronchiectatic lesions, though the actual tuberculous process is frequently quiescent or healed. Similarly a few patients with " healed cavities" which have become secondarily infected with aspergillus fungus may also need surgery.

There is also the rare occurrence of the patient who gets recurrent attacks of pneumonitis and pleurisy secondary to a localized bronchostenosis, which can be treated only surgically. Temporary antituberculous chemotherapeutic cover during, and a few weeks after, operation (which is usually a conservative resection) is advisable.

Sometimes the thoracic surgeon may be asked to consider early resection of a tuberculous lesion for what is said to be a social or occupational reason. This fifth group may include patients, such as alcoholics or those with mental illness, whose attendance at hospital is likely to be irregular, and occasionally patients such as seamen, who, if unwilling to submit to treatment, are apt to cause cross-infection in enclosed communities. Nevertheless, this indication should be accepted only with considerable reserve, as modern chemotherapy is adequate to deal with these lesions, and the patient should be pressed to co-operate for the necessary time. This indication varies widely from unit to unit and is probably a commoner indication for surgery in the United States, as H. T. Langston and his colleagues ${ }^{1}$ have pointed out.

Lastly, there is a small group of patients who have tuberculous disease of the lungs in association with other diseasessuch as cancer or congenital heart disease-and its treatment may present special problems and require early operation.

The standard methods of diagnosis and investigation of patients with pulmonary tuberculosis have been unaffected by the decline in the amount of surgical treatment. Nevertheless, bronchoscopy is still an important investigation in any patient who requires surgery. The number of cases of endobronchial lesions reported is now extremely small owing to efficient drug therapy, but it is still important that these should be looked for before surgery is carried out. The commonest operations used are still lobectomy or segmental resection of the lung for localized tuberculous foci, and occasionally pneumonectomy is needed for widespread tuberculosis, and-particularly if the pleura is involved-pleuropneumonectomy is required as well. Nevertheless, thoracoplasty still has a place, particularly in patients who are left with upper lobe cavitation, a positive sputum and possibly an organism resistant to several of the available agents, and, lastbut most important-a limited lung reserve. A combination of resection and a limited thoracoplasty is sometimes valuable in the treatment of upper lobe lesions, either performed at the same time or more usually with the resection first and the thoracoplasty second. The indication for this procedure is

\footnotetext{
1 Langston, H. T., Barker, W. L., and Pyle, M. M., Ann. Surg., 1966,

2 Chesterman, J. T.. Thorax, 1957, 12, 159.
} 
usually a persistent air space or the risk of emphysema developing in the residual lobe of the lung, or an exacerbation of the disease in the lobe.

A rare but associated problem to that of pulmonary tuberculosis, which arises particularly in children, is the treatment of tuberculous mediastinal glands. These can enlarge and press on or ulcerate into the bronchus. Repeated piecemeal bronchoscopic debridement is often required to restore the bronchial lumen and maintain normal lung function beyond it. If bronchoscopic aspiration is unsuccessful with a florid primary tuberculous infection of this type, thoracotomy and excision or evacuation of the glands may be required. This procedure is particularly valuable in preventing irreversible damage in the peripheral bronchi beyond the narrowed area. ${ }^{2}$

Langston and his colleagues have drawn attention to the recent increase in the study of atypical mycobacteria, which has resulted largely because of the greatly increased use and refinement of cultures for studying sputa. These organisms present varying problems of sensitivity, and in their view surgical intervention may have to be accepted earlier in patients infected by atypical organisms than in ordinary cases of infection with Mycobacterium tuberculosis.

The aim of surgery in pulmonary tuberculosis is still to be as conservative as possible, and careful preoperative investigation and proper surgical technique should enable the minimal amount of lung to be removed to achieve a satisfactory end result.

\section{No Change}

In these times of opinion polls and " random" surveys there is something refreshingly solid and reliable about a ballot. At the Annual Representative Meeting in 1966 the principle of merit awards was under discussion and it was resolved ${ }^{1}$ "that a postal ballot should be undertaken of all consultants and senior hospital staff and senior registrars to ascertain their views in respect of merit awards for consultants." The results are published at p. 22 of this week's Supplement.

The overall impression given by the response to the questions asked is that senior hospital staff are satisfied with the present system of merit awards. Despite considerable publicity in the B.M.F. and the Lancet only half the doctors concerned took part in the investigation. Not surprisingly, $95 \%$ of those with awards who replied were in favour of their continuation, though nearly half of them thought some changes were needed in the system. Even of those without awards $65 \%$ favoured their retention ; but $80 \%$ of this group thought changes should be made in the system of distribution. The ballot papers asked what changes in the system were desirable. Though many comments were made there was little agreement on what features needed reform. Secrecy was the most popular subject for comment-but even here only a fifth of those replying mentioned it. The form of the questions may have caused doctors some difficulty, and the $50 \%$ poll detracts from the results, but nevertheless most hospital doctors in the senior grades seem happy with the system of merit awards, and no feature is widely disliked. The constructive comments should not be ignored: but if democratic principles mean anything this ballot has produced a mandate for "no change."

\section{Stanley Morison and the B.M.J.}

Mr. Stanley Morison, who died last week at the age of 78 , was a typographer of world-wide renown; designer of the type-face known as Times New Roman, now used extensively in the printing of books, periodicals, and newspapers throughout the civilized world; at one time editor of The Times Literary Supplement; and the principal architect and author of the monumental five-volume History of The Times_." the solid historical and political foundations on which the whole structure rests were due to his astonishing (because it seemed to be effortless) power for research," to quote from the obituary in the newspaper whose history he helped to mould as well as record. Stanley Morison was a great scholar and a great man who profoundly influenced those fortunate to know him. His contributions and distinctions were recorded in the biography published in The Times last week. What may be not well enough known is the part he played in the history of the British Medical fournal when his advice as a typographer was sought in 1935 . It is therefore fitting that we should report at this time some of the facts of his beneficent intervention in the affairs of a periodical which thirty years ago looked-to use the description he then gave to the Journal Committee-more like the boiler-makers' magazine than the weekly journal of a learned profession. The rich overtones of his laughter as he passed this apt judgement removed all possible offence from it.

The scene on which Morison appeared in 1935 was one of some concern about the affairs of the B.M.F.: about its contents, its circulation, its physical appearance, and about the method of printing it and methods of management. It was not long before Morison had persuaded the Journal Committee that in the approaching reform the sham Gothic of the title on the cover should go. From that as a startingpoint he went in detail through the whole of the B.M.f., relating the changes he proposed to the significance of its different sections. He was soon invited to turn his attention to the various operations of producing the journal, and increasingly his advice on them was taken. A turning-point in this investigation was his recommendation that the composing-room immediately above the editorial offices should be abolished. The Council of the B.M.A. finally, after much debate and some close voting, accepted the Journal Committee's recommendation that this should be done, and accepted the consequences that flowed from it. And so when the B.M.F. made its first appearance in its new dress in 1937 the composing-room on the fourth floor of the north side of B.M.A. House was being dismantled, and the new journal was then composed and machine-printed for the first time by one and the same printer. This inevitably led to changes in managerial structure. The sum total of these changes altered the fortunes of the B.M.F. to the great financial advantage of the B.M.A. Many experts were consulted on the way to this radical reform. But if there is one man to whom in retrospect we may turn for special praise and thanks it is $\mathrm{Mr}$. Stanley Morison. He gave the Journal Committee unstintingly of his unique experience, his wisdom, his practical sense, and his fearless integrity. This he continued to do for many years after the grand climax of the B.M.F.'s revolution had passed. It would, we believe, have pleased him to have in this brief commemorative tribute a few notes about a bypath in the history of journalism, one of many subjects he made his own and thereby made the world so much better informed and the richer for it. 